\title{
Erratum to: A Flexible Software Architecture for a Network of Heterogeneous Smart Cameras
}

\author{
Dominik Pieczyński, Marek Kraft ${ }^{(\bowtie)}$, and Michał Fularz \\ Institute of Control and Information Engineering, \\ Poznań University of Technology, Piotrowo 3a, 60-965 Poznań, Poland \\ marek.kraft@put.poznan.pl
}

\section{Erratum to:}

\section{Chapter 11 in: R.S. Choraś (ed.)} Image Processing and Communications Challenges 8 DOI: $10.1007 / 978-3-319-47274-4 \_11$

In the original version, the name of the first author was incorrect. Instead of "Dominik Pieczński" it should read as "Dominik Pieczyński". The original chapter was corrected. 